\title{
A PRELIMINARY STUDY OF EMPATHY IN ROMANIAN COLLEGE STUDENTS
}

\author{
Valentin LUPU \\ “Nicolae Bălcescu”Land Forces Academy, Sibiu, Romania \\ valilupu@aol.com
}

\begin{abstract}
The Interpersonal Reactivity Index is a self-report instrument used for assessing empathy. The theoretical model of empathy for IRI assumes that empathy is multidimensional in nature containing affective aspects (Empathic Concern and Personal Distress) and cognitive aspects (Perspective Taking and Fantasy). The objective of this study was to compare the level of empathy in Romanian college students to the level of empathy in American college students and to compare empathy in college students based on gender and field of study. The IRI was administered to a sample of 216 Romanian college students. We were interested only on Empathic Concern and Perspective Taking scales. The results revealed that Empathic Concern in Romanian college students is lower than in American college students, women score higher than men on the two scales used and students studying at humanities colleges have a higher Perspective Taking than students studying at science colleges. Our suggestion as a result of this study is to introduce more classes in the curriculum at the elementary school level to teach children empathy using diverse methods.
\end{abstract}

Keywords: empathy, empathic concern, perspective talking, college student

\section{Introduction}

In March 2014, the European Union Agency for Fundamental Rights published a detailed report about violence against women. Findings of this report showed that in Romania 3 of 10 women stated they were physically, verbally or emotionally abused beginning at the age of 15 , and only $14 \%$ reported these kinds of incidents to the police. In the first five months of 2008 there were $21.3 \%$ more rapes than in the same period in 2007, according to the Romanian Police report which was quoted in a report by the National Evaluation and Promotion Center for Wellness [1]. Save the Children Romania, in a national sociological study, discovered that $22 \%$ of children physically threatened another child, 19\% humiliated another child in public and $16 \%$ hit someone [2]. The prison system in Romania is over populated, and since 2008 there is a continual increase in the prison population. In addition, Romania has the highest percentage of citizens in EU prisons. Romania also has the highest rate of abortion in the European Union. In 2014, $30 \%$ of pregnancies ended in abortion.

William Chopik, professor at Michigan State University, led a study examining empathy by country in which Romania situated as having a low level of empathy [3]. Another study at Michigan State University conducted by Konrath and O'Brien in 2011 revealed that today a college student's level of empathy in the USA is about $40 \%$ lower than their counterparts 20 to 30 years ago [4].

Having all of this data in mind, this study is evaluating the level of empathy among Romanian college students and trying to identify if the empathy is in a decreasing mode or not.

\section{What Is Empathy?}

There is a variety of definitions for empathy. Some definitions focus on feeling 
a concern for other people that creates a desire to help them [5], [6] and others focus on the ability to perceive accurately how another person is feeling [7], [8] or knowing what the other person is thinking or feeling [9], [10]. Empathy, in a general sense, can be understood as the "reaction of one individual to the observed experience of others" [11].

There are two camps among researchers of empathy: ones who view empathy in terms of affect and ones who view empathy from a cognitive approach. Hogan [12] defines empathy as being the ability to assume the point of view of others. Mehrabian views empathy as an ability to assume others' emotional states. When it comes to defining empathy it is very hard to separate the two aspects mentioned above, thus Iannoti [13] believes that both aspects are essential. Coke, Batson and McDavis [5] advocated for empathy as being a two stage model: a cognitive process of taking another's perspective and an emotional response based on physiological arouse. Davis [14] also proposed that empathy is multidimensional in nature, containing the aspect of emotions (feeling, concern and compassion) and the aspect of cognition (comprehending another person's mental state). Davis believes empathy consists of a set of separate but related constructs. For this model he developed a self -report measure of empathy, the Interpersonal Reactivity Index (IRI).

The IRI is a 28 item scale with 4 subscales, each of them having 7 items. The four subscales are Empathic Concern (EC), Perspective Taking (PT), Fantasy scale (FS) and Personal Distress (PD). Perspective Taking (PT) and Fantasy Scale (FS) reflect the cognitive aspect of empathy and Empathic Concern (EC) and Personal Distress (PD) reflect the affective aspect of empathy. Emphatic Concerns (EC) measures the feelings of warmth, compassion and concern for others. Perspective Taking (PT) measure the spontaneous attempts to adopt the perspective of other people and see things from their point of view. Fantasy Scale (FS) measures the tendency to identify with characters in movies, novels, plays and other fictional situations and Personal Distress (PD) measures the feelings of unease and anxiety oriented towards the self within interpersonal situations. When IRI was initially validated, it produced internal consistency indices ranging from .71 to .77 [14], test - retest reliabilities ranging from .62 to $.71[15]$. Each of the items are rated using a five-point Likert scale ranging from 0 (does not describe me well) to 4 (describes me very well).

\section{Objectives Of The Study}

- To compare college students' empathy based on gender

- To compare the Romanian college students' empathy with American college students' empathy

- To compare college students' empathy based on their field of study

\section{Subjects And Procedure}

Subjects were 216 Romanian college students from major university centers across the country. There were 43 males and 173 females who participated in the study. Students were recruited mostly through a student organization that has offices in the major university centers, and some of these students recruited their colleagues to participate. 111 of the students are studying at humanities colleges and 105 of the students are studying at science colleges.

Each student completed an anonymous online IRI questionnaire. For this study we took in consideration just two subscales, Perspective Taking, and Empathic Concern. The test was not timed. The participation was voluntary and anonymous.

\section{Results}

After Davis finalized the construct of IRI he administered it to students from introductory psychology classes at The 
University of Texas at Austin. The means and standard deviations for the four IRI scales as a result of this testing are presented in the following table (Catalog of Selected Documents, 1980, 10, 85):

Table 1 The means and standard deviation for the four IRI scales Male ( $\mathrm{N}=579)$

Female $(\mathbf{N}=582)$

Fantasy

15.73

18.75

(5.60)

Perspective

Taking

Empathic

Concern
16.78

19.04

(4.21)
17.96

(4.85)

21.67

(3.83)

$\begin{array}{lll}\text { Personal } & 9.46 & 12.28 \\ \text { Distress } & (4.55) & (5.01)\end{array}$

As a result of our testing we obtained the following means and standard deviation for the two IRI scales that we used in this study:

\begin{tabular}{lll} 
& Male $(\mathbf{N}=\mathbf{4 3})$ & Female $(\mathbf{N}=173)$ \\
\hline $\begin{array}{l}\text { Perspective } \\
\text { Taking }\end{array}$ & 15.86 & 17.38 \\
& $(3.60)$ & $(4.36)$ \\
& & \\
Empathic & 16.84 & 20.71 \\
Concern & $(4.94)$ & $(3.65)$
\end{tabular}

An independent-samples t-test was conducted to compare empathic concern in Romanian male students and American male students. There was a significant difference in the scores for American male students $\quad(\mathrm{M}=19.04, \quad \mathrm{SD}=4.21) \quad$ and Romanian male students $(\mathrm{M}=16.84$, $\mathrm{SD}=4.94) \quad$ conditions; $\quad \mathrm{t}(620)=3.26$, $\mathrm{p}=0.0012$. Hedges' $\mathrm{g}$ measure of effect size is 0.51 indicating a medium effect size. Our results suggest that the empathic concern in Romanian male students is lower than in American male students.
For Perspective Taking there is not a significant statistical differences between Romanian male students $(\mathrm{M}=15.86$, $\mathrm{SD}=3.60)$ and American male students $(\mathrm{M}=16.78, \mathrm{SD}=4.72)(\mathrm{p}=0.21, \mathrm{~g}=0.19)$.

An independent-samples t-test was conducted to compare empathic concern in Romanian female students and American female students. There was a very significant difference in the scores for American female students $(M=21.67$, $\mathrm{SD}=3.83$ ) and Romanian female students $(\mathrm{M}=20.71, \quad \mathrm{SD}=3.65) \quad$ conditions; $\mathrm{t}(753)=2.93, \mathrm{p}=0.003$. Hedges' $\mathrm{g}$ measure 
of effect size is 0.25 indicating a small effect size. Our results suggest that the empathic concern in Romanian female students is lower than in American female students.

As a result of the t-test for Perspective Talking between Romanian female students $(\mathrm{M}=17.38, \mathrm{SD}=4.36)$ and American female students $(\mathrm{M}=21.67, \mathrm{SD}=3.83)$ there is not a significant statistical difference $(p=0.16$, $\mathrm{g}=0.12$ ).

Women tend to score higher than men on each of the four subscales of the IRI [15], so we were interested to see if this was the case in our situation.

An independent-samples t-test was conducted to compare Perspective Taking in Romanian female students and Romanian male students. There was a significant difference in the scores for Romanian male students $\quad(M=15.86, \quad \mathrm{SD}=3.60) \quad$ and Romanian female students $(\mathrm{M}=17.38$, $\mathrm{SD}=4.36)$ conditions; $\mathrm{t}(214)=2.11, \mathrm{p}=0.03$. Hedges' $g$ measure of effect size is 0.36 indicating a small - medium effect size. Our results suggest that Perspective Taking in Romanian female students is higher than in Romanian male students. Also the t-test conducted to compare Empathic Concern in Romanian female $(\mathrm{M}=20.71, \mathrm{SD}=3.65)$ and male $(\mathrm{M}=16.84, \mathrm{SD}=4.94)$ students showed a difference that is extremely statistically significant ( $p=0.0001, g=0.98$ ). Our study confirms that women tend to score higher than men on each of the two subscales of the IRI.

\begin{tabular}{|c|c|c|c|}
\hline \multicolumn{2}{|c|}{ Field of Study } & $\begin{array}{c}\text { Perspective } \\
\text { Taking }\end{array}$ & $\begin{array}{l}\text { Empathic } \\
\text { Concern }\end{array}$ \\
\hline \multirow[t]{3}{*}{ Humanities } & Mean & 18.02 & 20.38 \\
\hline & $\mathrm{N}$ & 111 & 111 \\
\hline & $\begin{array}{l}\text { Std. } \\
\text { Deviation }\end{array}$ & 4.409 & 4.344 \\
\hline \multirow[t]{3}{*}{ Science } & Mean & 16.09 & 19.47 \\
\hline & $\mathrm{N}$ & 105 & 105 \\
\hline & $\begin{array}{l}\text { Std. } \\
\text { Deviation }\end{array}$ & 3.873 & 4.067 \\
\hline \multirow[t]{3}{*}{ Total } & Mean & 17.08 & 19.94 \\
\hline & $\mathrm{N}$ & 216 & 216 \\
\hline & $\begin{array}{l}\text { Std. } \\
\text { Deviation }\end{array}$ & 4.259 & 4.227 \\
\hline
\end{tabular}

As showed in Table 3, students from humanities colleges scored higher than students from science colleges on the Perspective Taking score and the Empathic Concern score. The difference between the values of the Perspective Taking scale for students from humanities colleges $(\mathrm{M}=18.02, \mathrm{SD}=4.41)$ and students from science colleges $(\mathrm{M}=16.09, \mathrm{SD}=3.87)$ is
1.93. An independent t-test was conducted to compare Perspective Taking in students from humanities colleges and students from science colleges. There was a extremely significant difference in the scores of students from humanities colleges and students from science colleges $\mathrm{t}(214)=3.41$, $\mathrm{p}=0.0008$, with a medium effect size $\mathrm{g}=0.46$. The results suggest that the field of 
study does have an effect on Perspective Taking.

The difference between the values of the Empathic Concern scale for students from humanities colleges $(\mathrm{M}=20.38, \mathrm{SD}=4.34)$ and students from science colleges $(\mathrm{M}=19.47, \quad \mathrm{SD}=4.06)$ is 0.91 . An independent t-test was conducted to compare Empathic Concern in students from humanities colleges and students from science colleges. There was not a significant difference in the scores of students from humanities colleges and students from science colleges $\mathrm{t}(214)=1.59$, $\mathrm{p}=0.11$, with a very small effect size $g=0.21$. The results suggest that field of study does not have an effect on Empathic Concern.

\section{Discusions}

This study discovered that there is less Empathic Concern and Perspective Taking, which are the most important components of empathy, in Romanian college students. Empathic Concern in Romanian male and female college students is below the 1980 Empathic Concern means in American college students. Students tend to have a hard time agreeing with statements as, "I often have tender, concerned feelings for people less fortunate than me", or "I sometimes try to understand my friends better by imagining how things look from their perspective". The increase on financial interest, a desire to get rich as soon as possible, an increase on bullying in schools, the violence in family and society, a growing emphasis on the self, all confirm the decrease of empathy. The rise of the individualism in society [16], alienates us from thinking of others because our mind is preoccupied with self. Empathic Concern reflects the affective aspect of empathy, and a lower level can indicate a difficulty when it comes to recognizing emotions. Goleman [17] affirmed that the key to discerning others' feelings is the ability to read nonverbal channels of communication.

The finding that females tend to score higher than males on the IRI scale was not a surprise for us. One of the common beliefs in society is that women are more people oriented, more caring and more empathetic than men [18]. In the last few years there are studies which suggest that the gender difference may be due to the belief that women are expected to be more caring toward people, so their responses on self-evaluation tests are based on the expectation, not the reality. There are some recent studies that have found evidence of biological basis for differences in empathy [19].

The study revealed that field of study has an influence on Perspective Taking. The college students who study humanities have a higher level of Perspective Taking than college students who study science. Perspective Taking reflects the cognitive aspect of empathy and expresses the understanding of other people's mental state. An important factor that contributes to a higher level of Perspective Talking is the curriculum at humanities colleges. Students who are studying humanities have more courses which often require the ability to analyze human behavior and literature, so the skill of putting themselves in others' shoes is more developed. Students from science colleges should be encouraged to take more humanities classes or be part of poetry and literature clubs. Perspective Taking is very helpful in any relationship but especially within a couple relationship. High Perspective Taking characterizes successful people as effective leaders where social skills are necessary. High Perspective Taking is necessary in applying problem solving skills.

In the context of empathy decrease, one suggestion that I have is to teach children empathy in school using different methods as a way to raise the level of empathy. 


\section{References}

[1] http://insp.gov.ro/sites/cnepss/wp-content/uploads/2016/01/Analiza-de-situatie-20157.pdf

[2] http://salvaticopiii.ro/upload/p000600010001 Salvati\%20Copiii_Raport\%20bullying.pdf

[3] Chopik, W. J., O'Brien, E., \& Konrath, S. H., Differences in Empathic Concern and Perspective Taking Across 63 Countries, Journal of Cross-Cultural Psychology, 48. 2338, 2016.

[4] Konrath, S. H., Ho, M., \& Zarins, S., The strategic helper: Narcissism and prosocial motives and behaviors, Current Psychology, 35, 182-194, 2016.

[5] Coke, J., Batson, D., \& McDavis, K, Empathic mediation of helping: A two-stage model, Journal of Personality and Social Psychology, 36, 752-766, 1978.

[6] Batson, C. D., The altruism question: Toward a social psychological answer, Hillsdale, NJ: Lawrence Erlbaum Associates, 1991.

[7] Eisenberg, N., \& Miller, P. A., Empathy and prosocial behavior, Psychological Bulletin, 101, 91-119, 1987.

[8] Levenson R.W., Rueff, A.M., Empathy: A physiological substrate, Journal of Personality and Social Psychology, 63, 234-346, 1992.

[9] Kohler, W., Gestalt psychology, New York: Liveright, 1929.

[10] Ickes W., Stinson L., Bissonnette, V., Garcia, S., Naturalistic social cognition: Empathic accuracy in mixed-sex dyads, Journal of Personality and Social Psychology, 59, 730 $742,1990$.

[11] Davis, M. H., Measuring individual differences in empathy: Evidence for a multidimensional approach, Journal of Personality and Social Psychology, 44, 113-126, 1983.

[12] Hogan, R., Development of an empathy scale, Journal of Consulting and Clinical Psychology, 33(3), 307-316, 1969.

[13] Iannotti, R., The elements of empathy. Paper presented at the Biennial meeting of the Society for Research in Child Development, San Francisco, 4, 1979.

[14] Davis, M. H., Empathy: A social psychological approach, CO: Westview Press, 1994.

[15] Davis, M. H., A multidimensional approach to individual differences in empathy. JSAS Catalog of Selected Documents in Psychology, 10, 85, 1980.

[16] Santos, H. C., Varnum, M. E. W., \& Grossmann, I., Global Increases in Individualism Preprint. Retrieved from osf.io/hynwh, March, 2017.

[17] Goleman, D., Emotional Intelligence: Why it can matter more than IQ, London: Bloomsbury, 1996.

[18] Rueckert, L., Gender differences in empathy. In Psychology of Empathy, 221-234, 2011.

[19] Knickmeyer, R., Baron-Cohen, S., Raggatt, P., Taylor, K., \& Hackett, G., Fetal testosterone and empathy, Hormones and Behavior, 49, 282-292, 2006. 